\title{
18F-FDG-PET/CT IDENTIFIES ACTIVE DISEASE IN TREATED TAKAYASU'S ARTERITIS
}

MARÍLIA PAULA SOUZA SANTOS (UNICAMP, Campinas, SP, Brasil), Celso Dario Ramos (Unicamp, Campinas, SP, Brasil), Mariana Paixão Ribeiro (Unicamp, Campinas, SP, Brasil), MANOEL BARROS BERTOLO (Unicamp, Campinas, SP, Brasil), Zoraida Sachetto (Unicamp, Campinas, SP, Brasil)

\section{BACKGROUND}

Fluorodeoxyglucose F18 - Positron-emission tomography (18F-FDG PET/CT) is contraditory in follow-up of patients with Takayasu's Arteritis. This study evaluated the utility 18F-FDG PET/CT for detect active disease in patients under immunossupression.

\section{MATERIALS AND METHODS}

Diagnosis of Takayasu's Arteritis was in agreement of the American College of Reumatology (1990). All patients were underwent whole-body 18F-FDG PET/CT. Qualitative analysis were classified by a 3-scale visual analysis using the liver and left atrium uptake as reference. A quantitative analysis was also performed by measuring the maximum standardized uptake value (SUV) of the vascular wall of some selected arteries, affected or not by the disease. Disease activity using the NIH criteria was also evaluated.

\section{RESULTS}

Total of 21 patients, 19 females and 2 males, mean age $40.5( \pm 11.56)$ years, disease duration $8.3( \pm 6.25)$ years. Fourteen (67\%) patients were in inflammatory active according to the criteria proposed by NIH. All patients were under treatment with immunosuppressive and/or immunobiological agents. Eighteen $(85,7 \%)$ was taking prednisone. In visual analysis, twenty pacients $(95,2 \%)$ had uptake $\geq 2$ in relation to the liver and the left atrium at least one vascular site. In quantitative analysis, the highest SUV value found was 19.2 in carotid artery and the lowest SUV value was 2.9 in subclavian artery. The mean maximum SUV did not differ between the clinically active and the inactive patients.

\section{CONCLUSION}

This study demonstrated that 18F-FDG PET/CT is an imaging method able to assess TA activity in a tranversal analysis. In TA, patients may have inflammatory vascular activity without clinical evidence. This result show that 18F-FDG PET/CT recognize subclinical active even in patients receiving immunossupressive treatment. 